\title{
WHAT IS PRIMARY CARE?
}

\author{
CHERYL HAWK, DC, PHD $^{a}$
}

${ }^{a}$ Professor and Director of Chiropractic Sciences, Palmer College of

Chiropractic, Davenport, IA.

Submit requests for reprints to: Cheryl Hawk, DC, PhD, 1000 Brady Street, Davenport, IA 52804. E-mail: hawk_c@palmer.edu Paper submitted May $30,2002$.

\section{INTRODUCTION}

Of all the developed countries, U.S. health care has the highest costs and the lowest patient satisfaction (1). Significant problems exist in the 3 core categories of cost, access and quality $(2,3)$. Runaway health-care costs have not yet been adequately reigned in, despite the advent of managed care. In fact, health-care costs rose markedly in 2000, and in conjunction with the smaller increases in the preceding 2 years indicate a reversal in the previous trend toward decreased costs (4). Access to health care in the U.S. is still inequitable, varying particularly with age, geographic region and socioeconomic status (5). Quality, assessed by health status, health outcomes, and appropriate use of technology and treatments, also varies considerably by demographics and region.

Over the past 40 years, primary care (PC) has been proposed as a solution to these problems (1). This paper will describe the development of the concept and definitions of PC in the U.S., with reference to their relationship to chiropractic practice in the present and future.

\section{DISCUSSION}

\section{Background of Primary Care in the U.S.}

The concept of PC has gone through a long period of development beginning in the 1960's and not complete even now. The changing face of PC is partly responsible for the considerable confusion and dispute surrounding its definition. Other contributing factors are turf battles over portal of entry into the health-care system and status differential between specialists and generalists. Perhaps the most basic contributing factor to the confusion over the definition of $\mathrm{PC}$, however, is the fact that it is a multidimensional concept. This means that, as in the story of the blind men and the elephant, the definition of PC depends on which dimension one is describing (6).

In 1996, the Institute of Medicine (IOM) categorized the definitions of PC by dimension as follows (6):
1. The entry point into the health care system

2. Care provided by a specified class of clinicians

3. A specified set of activities

4. A specified set of attributes

5. A strategy for organizing an entire health-care system

Perhaps the simplest starting point for defining PC is the IOM's 1996 characterization of it as "care positioned between self-care and the remainder of the clinical enterprise" (6, p. 76). How this statement is fleshed out, and how each of the dimensions listed above are described, has changed over the past 40 years, and these changes will be summarized below.

\section{Identification of the Need for Primary Care: the 1960's}

The term "primary care" first entered the health-care scene in $1961(7,8)$. PC was identified as a response to a number of factors which were contributing to the increasing cost and decreasing quality of American health care. These were seen as primarily related to:

- Increasing technology

- Specialization

- Hospital-based care

- Depersonalization of care

The 1966 Millis Commission report defined PC in terms of the physician. This report characterized the primary care physician as "the primary medical resource and counselor to an individual or family" (8). The PC physician arranges the services of specialists or hospitalization for the patient but retains his or her "continuing and comprehensive responsibility" (8).

\section{Differentiation of Primary Medical Care and Primary Health Care: the 1970's}

Alpert and Charney's 1973 monograph differentiated primary medicine, which delivers personal health services, from public health, which delivers community health services (9). Primary medical care was said to focus on 1) first contact care; 2) continuity of care for individual patients; 3 ) integration of services, including referrals $(9,10)$.

During this era in the U.S., primary care became clearly identified as a medical discipline delivering curative care, specializing in early intervention and continuity of 
care (11). The 1978 definition of PC by the IOM summarizes this position: "Primary care is accessible, comprehensive, coordinated and continual care delivered by accountable providers of personal health services" (12).

Outside the U.S.-even just across the border, in Canada-PC developed more in the direction of public health, emphasizing the health of the community, prevention and health promotion (13). The concept of a community orientation, rather than orientation exclusively toward the individual, is summarized in the World Health Organization's (WHO) 1978 report on PC. WHO defines PC as "essential health care" that is "universally accessible to individuals and families in the community," and involves their "full participation" in their care, at costs "affordable to the community" (14).

Table 1 summarizes major differences between primary medical care and primary health care.

\section{Community-oriented Primary Care: the 1980's}

The concept of integrating personal and public health in PC was further developed in the 1980's in the model of community-oriented primary care (COPC), first explicated in 1983 by Abramson and Kark $(15,16)$.

COPC is based on the ecologic model of health care service delivery, rather than the biotechnologic model that predominates in the U.S. The ecologic model is informed by the perspective, commonly held until the 19 th century and the industrial revolution, that health is a natural state affected chiefly by lifestyle and the environment (1). This model has considerable evidence to support it: even in the U.S., the most significant improvements in increasing lifespan are the result of public health measures such as water treatment systems and economic circumstances resulting in improved nutrition, rather than any type of curative care (1). COPC emphasizes prevention of disease and disability through community measures like health protection and access to basic preventive and anticipatory care. It is a community-based model rather than a personal service-based model, requiring centralized systems for surveillance and assessment of community needs (1). This is very different from the traditional organization of health services in the U.S., which is based on delivering treatment to individuals without regard for the community context.

Perhaps because of its considerable difference from the biotechnologic model, COPC did not catch on in U.S. However, because of the weight of evidence for its effectiveness in reducing costs and improving health, it did influence future definitions of primary care and remains an unrealized ideal in health care in this country. Its primary conceptual influences on PC definitions are $(1,17)$ :

- Community, rather than individual, perspective

- Shift in physician training from hospitals to community sites

\section{New Elements in the Definition of Primary Care: 1990 's}

The influence of COPC from other countries and the rise of managed care and integrated delivery systems affected the development of the next iteration of PC. The 1994 IOM definition incorporated previous elements but included several new ones, based on those influences. This definition is: "Primary care is the provision of integrated, accessible health care services by clinicians who are accountable for addressing a large majority of personal health care needs, developing a sustained partnership with patients, and practicing in the context of family and community." (7)

The most notable new elements were the addition of the terms, "integrated," "partnership," and "community." Clearly, the emphasis remained on personal health services, but an attempt to connect PC with the community was incorporated. It is also significant that

TABLE 1.

Comparison of Primary MEdical CARE ANd PRIMARY HEALTH CARE.*

\begin{tabular}{|c|c|c|}
\hline $\begin{array}{c}\text { CHIEF CHARACTERISTICS } \\
\text { OF CARE }\end{array}$ & $\begin{array}{c}\text { PRIMARY } \\
\text { MEDICAL CARE }\end{array}$ & $\begin{array}{l}\text { PRIMARY } \\
\text { HEALTH CARE }\end{array}$ \\
\hline Focus & CURATIVE (SECONDARY/TERTIARY PREVENTION) & ANTICIPATORY (PRIMARY/SECONDARY PREVENTION) \\
\hline TYPE & TREATMENT (REDUCE SYMPTOMS) & HEALTH PROMOTION \\
\hline TIMING & EPISODIC & CONTINUOUS \\
\hline PROVIDERS & SPECIALISTS & GENERALISTS \\
\hline INTERACTION WITH PATIENTS & PHYSICIAN DOMINANCE & PATIENT PARTNERSHIP \\
\hline INTERACTION WITH COMMUNITY & PROFESSIONAL DOMINANCE & COMMUNITY PARTICIPATION \\
\hline
\end{tabular}

* Sources: Bower LB, MoOtz RD. THE Nature of primary CARE: the chiropractor's Role.

TOP CLIN CHIROPR 1995;2:66-84; AND HAWK C. CHIROPRACTIC AND PRIMARY CARE. IN: ADVANCES IN CHIROPRACTIC. DANA J. LAWRENCE, ED. ST. LOUIS: MOSBY-YEAR BOOK, 1996:287-318. $(5,10)$ 
the word "clinician" rather than "physician" is used, making it official that "physician extenders" like nurse practitioners and physician assistants were part of the primary care team (10).

\section{Re-Envisioning Primary Care for the Future: 2002}

With all the changes related to managed care, it appeared in the late 1990's and beginning of the new millennium that primary care, although a wellestablished concept, was not working out particularly well in actual practice (18). There are several problematic issues inherent in the current manifestation of PC practice. One is that PC practice is considered "second best" by both patients and physicians, with specialists still viewed as the deliverers of optimal care. Even C. Everett Koop did not make much of a dent in this attitude, with his statement, "to be a generalist is not to be something less than a specialist; the generalist is something more" (19). Practitioners who are not considered PC providers (PCPs) aspire to the position mainly due to its portal-of-entry function, not for its status or income. In fact, since managed care has positioned PCPs as gatekeepers, they are often viewed as nothing more than obstacles between patients and specialists (18).

A key issue to the problems with PC practice is the time constraints placed by managed care on PCPs. A related issue is the population shift toward chronic health problems that require more time to manage appropriately (18).

In order to revitalize PC and make it operate more efficiently and effectively in the future, the following mechanisms need to be either instituted or further developed (18):

1. Partnership between specialists and PCPs. "Specialists," in this context, might be extrapolated to include complementary and alternative medicine (CAM) providers as well, since patients often want to, and do, seek care from CAM providers but their PC physicians often do not communicate with or even know about them (20).

2. Partnership with "midlevel" practitioners. It is suggested that nurse practitioners and physician assistants handle uncomplicated cases, allowing the physician more time for patients with complex and/or chronic problems (18). Some might see this as the niche for CAM practitioners like chiropractors, but it is unlikely that chiropractors would welcome a position as "physician extenders."
3. Use of health informatics and other computer technology. Web-based and other computer technology could facilitate not only better use of evidence in individual case management, but also patient access, education, communication and scheduling (18).

4. Innovative insurance coverage methods. These include capitation plans covering yearly overall care for a patient or monthly access charges, replacing billing for specific visits and procedures (18).

Such methods could then be used in the service of optimization of PC practice, emphasizing these essential elements of PC in the future (18):

- Evidence-based practice

- Preventive, rather than episodic, care

- Personal interactions between provider and patient

\section{Defining Current Primary Care Practice}

This section will detail and discuss how the 1996 IOM dimensions of PC are currently manifested. These dimensions are: the entry point into the health care system; care provided by a specified class of clinicians; a specified set of activities; a specified set of attributes; and a strategy for organizing an entire health care system (6).

\section{Portal of Entry to the Health Care System}

This is the gatekeeper function, which is the chief political reason for providers as diverse as orthopedic surgeons, pharmacists and chiropractors to fight for the right to be considered "primary care." Today, integrated delivery systems are not "the only game in town;" many different types of insurance plans are available, only some of which require a PCP to function as gatekeeper (21). Consequently, the clamor of non-PCPs to gain PC status has diminished considerably. For example, chiropractors, who had been intent on PCP status in the early and mid-1990's, by the late 1990's did not prefer to seek conventional PCP status, according to a study published in 2000 (22). In many situations, patients are able to choose which provider they want as portal of entry for specific complaints. Due to this patient self-selection, chiropractors frequently serve as PCPs, particularly for patients with musculoskeletal complaints $(23,24)$. One practice-based research study showed that $66 \%$ of chiropractic patients aged 55 and older sought care only from a chiropractor for their chief complaint (99\% of which were musculoskeletal) (24).

\section{Care Provided by a Specific Class of Clinicians}

Although there is no Federal policy restricting PC to a specific group of providers, medical care has always been 
the status quo in the U.S. $(1,3)$. The U.S. Public Health Service Act designates "primary health services" to be provided by "physicians or other health professionals" in the specialties of family practice, internal medicine, gynecology, pediatrics, dentistry and mental health (25). The IOM definition of clinician, "an individual who uses a recognized scientific knowledge base and has the authority to direct the delivery of personal health services to patients" (6), does not functionally exclude chiropractors. Furthermore, some authors suggest that including chiropractors in this category could be costeffective $(26,27)$.

Chiropractors do, in fact, view themselves as PCPs (28), and their training prepares them to perform PC functions (29). However, other professions, the government and the public do not usually view them as such at this time $(22,30,31)$.

\section{Specific Activities}

As stated in the 1994 IOM definition of PC, these activities broadly encompass whatever is required to meet “... a large majority of personal health care needs ..." (7). The IOM report explains that this statement means that PCPs receive all patients' presenting problems, and are adequately trained to manage most of them, referring as appropriate. Furthermore, "personal health-care needs" are not restricted to physical problems but include mental, emotional, and social concerns affecting the patient's ability to function $(7,10)$. Thus the activities specific to PC are actually very nonspecific, encompassing as they must whatever is needed to diagnose and treat the most common complaints of the general population, including education and counseling needs as well (32). What is perhaps most characteristic of primary care activities is that they address illness before it becomes severe $(3,17)$.

The key consideration in determining whether it is within the scope of chiropractic practice to be able to address the majority of patients' personal health needs is really a conceptual, paradigmatic one the answer depends on whether one is operating within the primary-medical-care or primary health-care model $(5,33)$. Within the primary medical-care model, it is unthinkable that a clinician could address the majority of patients' health care needs without drugs $(34,35)$. Within the primary health-care model, it is possible that a clinician might very appropriately manage the majority of patients' presenting complaints without using drugs as the preferred approach to care, recognizing when it is necessary to refer patients to other providers for more invasive treatment such as drugs or surgery (5). Such an approach is, in fact, entirely congruent with chiropractic practice $(36,37)$.

\section{Specific Attributes}

A separate dimension from the type of services delivered in PC practice is the type of attributes characterizing the manner in which the services are delivered. The attributes contained in the 1994 IOM definition, "Primary care is the provision of integrated, accessible health care services by clinicians who are accountable for addressing a large majority of personal health care needs, developing a sustained partnership with patients, and practicing in the context of family and community" (7), have been operationalized into measurable factors in the Components of Primary Care Instrument $(38,39)$. This patient selfreport questionnaire has been used to assess both familypractice medical physicians and chiropractors $(39,40)$. However, the assessments were done separately, with somewhat different methodology. One was done through a national chiropractic practice-based research program with primarily independent practitioners (40). The other was done in a practice-based research program operating among community-based family practice physicians and nurse practitioners in managed-care settings (39). Therefore, one must be cautious in comparing the results directly. Even with this caveat, it is important to note that the scores for both groups were very similar for all components except coordination and comprehensiveness of care, in which chiropractors' scores were lower. Table 2 compares the scores for participants in these two studies.

\section{Specific Strategy for Health Care Organization}

This refers to an ambulatory care model emphasizing community-based prevention, one that has not been implemented successfully in the U.S. at this time. COPC, as described above, is still more of an ideal than a reality. The Healthy People 2010 initiative, which established the blueprint for improving the health of Americans, reinforces the need for greater integration of personal and community health services, particularly to deliver preventive and health promotion services to the public (41). The U.S. government supports the integration of personal and community-based health services, through such programs as those developing and maintaining Area Health Education Centers, Community Health Centers, and Rural Health Centers. The U.S. Health Resources and Services Administration Bureau of Health Professions has funded, and continues to fund, a number of training programs for all the health professions, including chiropractic, for the purpose of improving delivery of primary care in the U.S. (42). 
TABLE 2.

CHIROPRACTORS' AND FAMILY PRACTICE PRACTITIONERS' SCORES ON THE COMPONENTS OF PRIMARY CARE INSTRUMENT.*

\begin{tabular}{lll}
\hline \multicolumn{1}{c}{ COMPONENT } & DC $^{1}$ & MD $^{2}$ \\
\hline PATIENT ADVOCACY & 5.20 & 5.09 \\
INTERPERSONAL COMMUNICATION & 5.10 & 5.01 \\
ACCUMULATED KNOWLEDGE & 4.55 & 4.77 \\
COMMUNITY CONTEXT & 4.31 & 4.40 \\
FAMILY CONTEXT & 4.12 & 4.46 \\
COORDINATION OF CARE & 4.08 & 4.91 \\
COMPREHENSIVENESS OF CARE & 3.89 & 5.12 \\
\hline
\end{tabular}

* Scores REPRESENT INDEX SCORES for ITEMS CONSTITUTING EACH COMPONENT. PATIENTS' RESPONSES TO QUESTIONS WERE GIVEN ON A SIX-POINT LIKERT SCALE ANCHORED BY "STRONGLY DISAGREE" AND "STRONGLY AGREE." ITEMS WERE SCORED SO THAT HIGHER SCORES REPRESENT MORE POSITIVE RESPONSES.

1 PATIENT $N=2,987$ FOR THE ENTIRE STUdy. SOURCE: HAWK C, LONG CR, BOULANGER K. PATIENT SATISFACTION WITH THE CHIROPRACTIC CLINICAL ENCOUNTER: REPORT FROM A PRACTICE-BASED RESEARCH PROGRAM. J NEUROMUSCULOSKELETAL SYSTEM 2OO1;9(4): 109-1 17. (24)

2 PATIENT $N=1,475$ FOR THE ENTIRE STUDY. FIGURES ABOVE REPRESENT SCORES OF PATIENTS IN PRACTICES OF MEDIUM ORGANIZATIONAL RESTRICTIVENESS ( $N=312$ ); HOWEVER, VARIATION AMONG SCORES OF PATIENTS IN OTHER MANAGED CARE CATEGORIES WAS NOT Significant. SOURCE: Flocke SA, Orzano AJ, SELINGER A, WERnER JJ, VOREL L, NUTTING PA, StANge KC. DOES MANAged CARE RESTRICTIVENESS AFFECT THE PERCEIVED QUALITY OF PRIMARY CARE? A REPORT FROM ASPH. J FAM PRACT 1999;48(10):762-768. (39)

Although only a small number of chiropractors have participated in these efforts to integrate personal and public health services, there have been a number of small but very successful projects involving chiropractors in both public health and interdisciplinary training and activities across the country over the past decade (42-47).

\section{CONCLUSION}

Primary care, although by no means a new concept in health care, has not yet found its optimal iteration in the U.S. health care system. There is a clear need for health care providers who are generalists, provide longitudinal care, maintain a close doctor-patient relationship with patients and their families, work in partnership with other providers and the community to deliver preventive and health promotion services and provide, as stated in the 1996 IOM report, "care positioned between self-care and the remainder of the clinical enterprise" (6, p. 76). Medical physicians have not, to date, adequately filled this role, although it is expected that with the assistance of midlevel practitioners they may be able to do so in the future $(1,6,7)$. There is evidence that chiropractors could perform many of the functions required by $\mathrm{PC}$ and that a majority of them feel that they do function as PCPs $(10,24,27,28,32,40)$. On the other hand, there is also evidence that the rest of the health-care community does not view them as such, and that a substantial proportion of chiropractors themselves do not wish to pursue this direction $(6,7,22,30,35)$. For the health of Americans, the American health-care system, and the chiropractic profession itself, it is important that the profession analyze its possible future roles in $\mathrm{PC}$, choose the most appropriate one and make a concerted effort to adopt it.

\section{REFERENCES}

1. Wright RA. Community-oriented primary care: the cornerstone of health care reform. JAMA 1993;269:2544-47.

2. Engel GL. The need for a new medical model: a challenge for biomedicine. Science 1977;196:129-36.

3. Starfield B, Simpson L. Primary care as part of US health services reform. JAMA 1993:269:3139.

4. Heffler S, Smith S, Won G, Clemens MK, Keelan S, Zezza M. Trends: Health spending projections for 2001-2011: the latest outlook. Health Affairs 2002;21:207-18.

5. Bower LB, Mootz RD. The nature of primary care: the chiropractor's role. Top Clin Chiropr 1995:2:66-84

6. Donaldson M, Yordy K, Lohr KN, Vanselow N, eds. Primary care: America's health in a new era. Washington, DC: National Academy Press; 1996.

7. Donaldson M, Yordy K, Vanselow N, eds. Defining primary care: an interim report. Washington, DC: National Academy Press; 1994.

8. Millis JS. The graduate education of physicians. Chicago, IL: American Medical Association; 1994.

9. Alpert JJ, Charney E, eds. The education of physicians for primary care. Washington, DC: U.S. Department of Health, Education and Welfare; 1973.

10. Hawk C. Chiropractic and primary care. In: Lawrence DJ, ed. Advances in Chiropractic. St. Louis, MO: Mosby-Year Book; 1996. P. 287-318.

11. Gonnella J, Cattani K, Louis D. Use of outcome measures in ambulatory care evaluation. In: Gieabink G, White N, Short E, eds. American Ambulatory Medical Care-Quality Assurance 1977. La Jolla, CA: La Jolla Health Science Publications; 1977.

12. Institute of Medicine. A manpower policy for primary care: A report of a study. Washington, DC: National Academy Press; 1978.

13. Lalonde M. A new perspective on the health of Canadians. Ottawa, Canada: Ministry of National Health and Welfare; 1974.

14. World Health Organization. Alma-Ata 1978: Primary health care. Geneva: World Health Organization; 1978.

15. Abramson J, Kark SL. Community-oriented primary care: meaning and scope. In: Institute of Medicine, ed. Community-oriented Primary Care-New Directions for Health Services. Washington, DC: National Academy Press; 1983. P. 21-59.

16. Geiger HJ. Community-oriented primary care: the legacy of Sidney Kark. Am J Public Health 1993;83:946-47.

17. Fulmer HS, Cashman S, Hattis P. Bridging the gap between medicine, public health, and the community: PATCH and the Carney Hospital experience. J Health Educ 1992;23:167-70.

18. Scherger JE. Challenges and opportunities for primary care in 2002. Netscape Family Medicine 2002.

19. Koop CE. A general and primary solution for American health care problems. Acad Med 1993;68:46-7.

20. Eisenberg DM, Davis RB, Ettner SL, Appel S, Wilkey S, Van Rompay M, Kessler R. Trends in alternative medicine use in the United States, 1990-1997: results of a follow-up national survey. JAMA 1998;280: 1569-75.

21. Pelletier KR, Astin JA, Haskell WL. Current trends in the integration and reimbursement of complementary and alternative medicine by managed care organizations (MCOs) and insurance providers: 1998 update and cohort analysis. Am J Health Promotion 1999;14:125-33.

22. Teitelbaum $M$. The role of chiropractic in primary care: findings of four community studies. J Manipulative Physiol Ther 2000;23:601-9.

23. Hampe S. AMJ special report: primary care chiropractors: solving the shortage? Alternative Med J 1995;2:11-15. 
24. Hawk C, Long CR, Boulanger K, Morschhauser E, Fuhr A. Chiropractic care for patients aged 55 years and older: report from a practice-based research program. J Am Geriatr Soc 2000;48:534-45.

25. Budetti PP. Achieving a uniform federal primary care policy. JAMA 1993; 269:498-501.

26. Benko LB. Managed care. Alternative medicine cuts costs as therapy. Modern Healthcare 2000;30:50.

27. Anonymous. The AMI model: new picture of health. J Am Chiropr Assoc 2001;38:32-3.

28. Hawk C, Dusio ME. A survey of 492 US chiropractors on primary care and prevention-related issues. J Manipulative Physiolog Ther 1995;18:57-64.

29. American Chiropractic Association. ACA position on primary care. Am Chiropr Assoc: for Your Information 1994; August/September.

30. Hawk C. Should chiropractic be a "wellness" profession? Top Clinical Chiropr 2000;7:23-6.

31. Coulter ID. Is chiropractic care primary health care? J Canadian Chiropr Assoc 1992;36:96-101.

32. Kranz KC. An overview of primary care concepts. Top Clinical Chiropr 1995; 2:55-65.

33. Hawk C. The wellness hypothesis. In: Leach R, ed. The Chiropractic Theories, 4th ed. Baltimore, MD: Williams \& Wilkins; 2002.

34. Ebrall PS. Chiropractic and cul-de-sac. Chiropr J Aust 1994;24:106-12.

35. Nelson CF. Chiropractic scope of practice. J Manipulative Physiol Ther 1993; $16: 488-97$.

36. Winterstein JF. Philosophy of chiropractic: a contemporary perspective: Part 1. J Am Chiropr Assoc 1994;31:28-36.

37. Winterstein JF. Philosophy of chiropractic: a contemporary perspective: Part 2. J Am Chiropr Assoc 1994;31:64-71.
38. Flocke SA. Measuring attributes of primary care: development of a new instrument. J Fam Pract 1007;45:64-74.

39. Flocke SA, Orzano AJ, Selinger A, Werner JJ, Vorel L, Nutting PA, Stange KC. Does managed care restrictiveness affect the perceived quality of primary care? A report from ASPH. J Fam Pract 1999;48:762-68.

40. Hawk C, Long CR, Boulanger K. Patient satisfaction with the chiropractic clinical encounter: report from a practice-based research program. J Neuromusculoskeletal System 2001;9:109-17.

41. U.S. Dept. of Health and Human Services. Healthy People 2010: Understanding and Improving Health. 2nd edition. Washington, D.C.: U.S. Government Printing Office, November 2000

42. Hawk C, Nyiendo J, Lawrence D, Killinger LZ. The role of chiropractors in the delivery of interdisciplinary health care in rural areas. J Manipulative Physiolog Ther 1996;19:82-91.

43. Perillo M, Hawk C, Anderson E. A model course for public health education in chiropractic colleges: a project status report. Proceedings of the 129th Annual Meeting of the American Public Health Association. October 2001

44. Hawk C, Killinger L, Perillo M, Colley F, Baird R, Victory K, Flora H. Development of a model course for public health in chiropractic colleges. Proceedings of the 127th Annual Meeting of the American Public Health Association. November 1999.

45. Hawk C, Buckwalter K, Byrd L, Cigelman S, Dorfman L, Ferguson K. Health professions students' perceptions on interprofessional relationships. Acad Med 2002;77:81-4.

46. Hawk C, Byrd L, Killinger LZ. Evaluation of a geriatrics course emphasizing interdisciplinary issues for chiropractic students. J Gerontol Nurs 2001;27: 6-12.

47. Krishnan S, Victory K, Flora H. Public health in chiropractic colleges: a preliminary study. J Chiropractic Educ 1995;9:17-25. 